\title{
Sabores y olores en la novela policíaca de Jean-Claude Izzo: recetas de vida para una existencia cosmopolita
}

\author{
Jordi LUENGO LÓPEZ \\ Universidad Pablo de Olavide de Sevilla \\ jluengol@upo.es
}

Recibido: $27 / 10 / 2012$

Aceptado: 11/01/2013

\begin{abstract}
Resumen
La Marsella de Jean-Claude Izzo es una ciudad cosmopolita que suele oler a muerte. Ese hedor se extiende por toda la metrópolis envenenando irremediablemente el sabor de la vida. Fabio Montale, el detective protagonista de la trilogía policial de Izzo (Total Khéops, Chourmo y Solea), tendrá esa sensación muy presente a lo largo de todas sus aventuras. Con el fin de desembarazarse de ella, contrarrestará dicho resabio saboreando los distintos platos que la ciudad mediterránea le ofrezca, deleitándose con cada trago de alcohol y descubriendo la variedad de aromas que reposan sobre la piel de las mujeres a las que ame. Equiparándose al escritor belga George Simenon y al italiano Andrea Camilleri, Izzo introducirá también el placer del buen comer y beber en sus novelas policíacas, aunque sazonándolo, a su vez, con esa mezcla multicultural que caracteriza a Marsella.
\end{abstract}

Palabras clave: Jean-Claude Izzo, Fabio Montale, Marsella, novela policíaca, arte culinario.

\section{Goûts et odeurs dans le polar de Jean-Claude Izzo: recettes de vie pour une existence cosmopolite}

\begin{abstract}
Résumé
La Marseille de Jean-Claude Izzo est une ville cosmopolite où l'on sent souvent une odeur de mort. Cette puanteur se répand dans toute la métropole empoisonnant la saveur de la vie. Fabio Montale, le commissaire de la trilogie d'Izzo (Total Khéops, Chourmo et Solea) aura toujours présent à l'esprit cette sensation tout au long de ses aventures. Afin de se dépêtrer de celle-ci, il compensera cet arrièregoût en goûtant les différents plats que la ville méditerranéenne lui offre, en jouissant aussi de chaque gorgée d'alcool et en découvrant la variété de parfums qui reposent sur la peau des femmes qu'il a aimées. À l'instar de l'écrivain belge George Simenon et de l'Italien Andrea Camilleri, Izzo introduira aussi le plaisir du bon manger et du bon boire dans ses polars, mais en les assaisonnant, en plus, avec ce mélange multiculturel si caractéristique de Marseille.
\end{abstract}

Mots clés: Jean-Claude Izzo, Fabio Montale, Marseille, polar, art culinaire. 


\title{
Tastes and smells in the detective novels of Jean-Claude Izzo: recipes for a cosmopolitan life
}

\begin{abstract}
Jean-Claude Izzo's Marseilles is a cosmopolitan city with a pervasive smell of death. Its stench spreads across the city, irredeemably poisoning the flavour of life. For Fabio Montale, the detective protagonist of Izzo's trilogy (Total Khéops, Chourmo and Solea), this sensation is a constant thread running through all his adventures. In an attempt to rid himself of it, he counteracts its unpleasant aftertaste by savouring the range of dishes offered by the Mediterranean city, delighting in each shot of alcohol and discovering the aromas that lie under the skin of the women he loves. Like the Belgian writer George Simenon and the Italian novelist Andrea Camilleri, Izzo also introduces the pleasure of good food and drink into his detective novels, but seasoned at the same time with the multicultural mix characteristic of Marseilles.
\end{abstract}

Keywords: Jean-Claude Izzo, Fabio Montale, Marseilles, detective novel, culinary art.

\section{Referencia normalizada}

Luengo López, J. (2013). "Sabores y olores en la novela policíaca de Jean-Claude Izzo: recetas de vida para una existencia cosmopolita". Thélème, Vol. 28, 187-203.

Sumario: 1. Marsella, mezcla de belleza y angustia en una ciudad cosmopolita. 2. Rincones y lugares para sentarse a comer. 2.1. La Guía Michelin y el "efecto Izzo" 2.2. Un local de calor cosmopolita 2.3. Otros recovecos para un bien manger.3. Una filosofía para vencer a la muerte. 3.1. Para sentirse vivo hace falta comer 3.2. Una madre improvisada para un buen plato casero 3.3. Las recetas de JeanClaude Izzo. 4. El acompañamiento del alcohol. 4.1. El vino, la exquisitez en el paladar 4.2. El sortilegio del Lagavulin 4.3. El pastis, el arte de vivir marsellés. 5. Del sabor y perfume de la mujer marsellesa. 5.1. Aquello que Montale busca en las mujeres 5.2. La atracción de la exótica diversidad femenina. 6. Conclusión.

\section{Marsella, mezcla de belleza y angustia en una ciudad cosmopolita}

Marsella es una ciudad cosmopolita ${ }^{1}$. Todo viandante puede percibir esta realidad cuando decide deambular por el Vieux-Port, advirtiendo a cada paso el vínculo entre la ciudad y el mar Mediterráneo. Esa misma sensación ya fue recogida en los años noventa del pasado siglo, en un panfleto publicitario, ampliamente difundido por la ciudad y la región provenzal, donde podía leerse "Marseille 'carrefour du monde"" (Gastaut, 2003: 5). Pese a que han transcurrido dos décadas desde aquel

${ }^{1}$ En el presente siglo, según Yvan Gastaut, el cosmopolitismo atribuido a la ciudad de Marsella se encuentra vinculado a la noción de una diferencia tolerada, respetada y adaptada, por todos aquellos individuos que comparten ese mismo espacio físico (Gastaut, 2002: 3; Lassave, 1999: 20, 23-25). 
mensaje, el estatus de ciudad-enclave de distintos flujos migratorios a lo largo de la Historia continúa siendo el distintivo de la urbe. Marsella es un punto de encuentro donde confluyen una caleidoscópica variedad de culturas, cuya conformación se debe al gran número de personas que llegaron a esa encrucijada por distintas rutas de un mismo mar. Esto explica que Jean-Claude Izzo (1945-2000) sostenga que Marsella sólo puede ser descubierta por y a través del Mediterráneo (Izzo, 2006a: 304; citado en Puntí, 2009). Será, pues, esa primera visión de Marsella desde el mar la que permanecerá en las retinas del emigrante, quien, desde el instante en que tome tierra, volverá reiteradamente al lugar donde sintió por primera vez ese carrefour cosmopolita, para buscar, en la lejanía, un atisbo de lo que fue su hogar.

Al igual que ese emigrante ${ }^{2}$, Fabio Montale, el protagonista de la trilogía policíaca de Izzo, también saboreará el Mediterráneo, pero no sólo desde el recuerdo del tiempo pasado, sino que, además, buscará disfrutar de las sensaciones que Marsella le ofrece en su presente, a través de la comida, la bebida y de las relaciones con aquellas mujeres que, con su exotismo, sazonan el gusto por la vida. Para Fabio Montale, el horizonte también le brindará la reminiscencia de un hogar perdido, aunque éste se encontrará en el recuerdo de la infancia (Izzo, 2006b: 324). Cada vez que la tristeza le venza, recorrerá con su barco la bahía marsellesa, con el fin de hallar algún rincón tranquilo en las islas Frioul, donde poder sumergirse y recobrar, así, aquella felicidad ya olvidada. Un ensalmo que le hará caer en el convencimiento de que es en ese horizonte, en las aguas del Mediterráneo, donde se encuentra la solución a todas las contradicciones del alma humana. De ahí que desee disolverse en el suave murmullo de sus aguas, para resolver, al fin, todo aquello que quedaba por solucionar en su vida (Izzo, 1998: 40; 2006a: 85). El mar es, por lo tanto, una parte del espíritu de Fabio Montale, pero sobre todo lo es de la propia Marsella.

Izzo, además, sostiene que Marsella no es una ciudad para hacer turismo, porque no hay nada que ver. Su belleza no se fotografía, sino que se comparte. Uno tiene que apasionarse por formar parte de su universo, porque, sólo así, podrá contemplar la ciudad tal cual es (Izzo, 2006a: 75; Perron, 2003: 42). Si no se procede de este modo, difícilmente podrá advertirse la amplia gama de azules — clara metáfora de sus gentes - con los que se viste la ciudad portuaria:

Ce n'est qu'après que l'on découvre les bleus gris, les bleus noirs, et les bleus outremer, les bleus poivre, les bleus lavande, les bleus aubergine des soirs d'orage, les bleus verts de houle, les bleus cuivre de soleil ou ce bleu si pâle qu'il en devient blanc (Izzo, 2006b: 498-499).

Esta variedad de tonalidades hace de Marsella una ciudad eminentemente azul, bajo cuyo limpio cielo se agrupa la diversidad de gentes, sin que ello altere su color identitario. Este efecto de monocromática variedad cristaliza en las retinas de sus habitantes gracias a la luz de la cosmopolita ciudad francesa. Sus rayos son siempre

\footnotetext{
${ }^{2}$ Sírvase la utilización del masculino genérico para aludir tanto a mujeres como a hombres.
} 
palpables, incluso cuando su intensidad obliga a bajar los ojos de quienes la contemplan. Fabio Montale es consciente de este fenómeno, por lo que dejará que la luz de Marsella penetre en su interior, dado que considera que es la única sensación que puede equipararse a un sincero estado de bienestar: "la douceur du soleil sur mon visage. C'était bon. Je ne croyais qu'à ces instants de bonheur. Aux miettes de l'abondance" (Izzo, 2006b: 431; citado en Dhoukar, 2006: 35 y Puntí, 2009). Esta es, por lo tanto, la primera regla para apreciar la belleza de Marsella: aprender a sentir, y vivir, su luz y el mar que baña su orilla. En ese contexto ambiental e identitario, Montale iniciará un periplo por sus calles, con el objeto de degustar esas "miettes de l'abondance" localizadas en su comida y bebida, cuyo sabor le recordará constantemente la naturaleza cosmopolita de Marsella.

Sin embargo, en la obra de Izzo se advierte que cuando la vida apesta a muerte, el "apetito" por ésta deja de estar presente. Ese olor nauseabundo a podrido, a muerte, perseguirá a Fabio Montale a lo largo de la trilogía del autor marsellés. Dicha emanación se desprende de una sociedad corrupta, y pervertida moralmente, que Montale detectará con su olfato. Izzo dota a su protagonista de un don particular, puesto que éste no sólo será capaz de percibir el aroma de los buenos platos o las esencias de la piel de las mujeres que ame, sino que también advertirá el olor que desprende la sociedad marsellesa en general.

Como buen conocedor de los entramados corruptos de la ciudad portuaria, el hedor que acompañará siempre a Fabio Montale será el de la muerte. Una intensa pestilencia que se pegará a su piel, sin posibilidad alguna de desprenderse de ella: "la mort ne me lâchait plus, comme un espèce de poisse dans laquelle, un jour, j'avais dû foutre les pieds" (Izzo, 2006b: 350; 1998: 199; 2006a: 128). Una hediondez que estaba condenado a soportar, dado que, durante sus años como policía, había conseguido imponerse en su olfato por encima de todos los demás olores. Ignoraba éste si, en Marsella, se moría más que en otros lugares, pero era evidente que la muerte se extendía por todas partes: "la vie puait la mort et les cauchemars n'existent que dans la vie" (Izzo, 1998: 79, 257). Para poder librarse de ese olor, al final del primer volumen, Total Khéops, Montale decide abandonar el cuerpo de policía, pero esa nauseabunda pestilencia continuará a lo largo de las dos historias siguientes.

Desde antes de que empezaran sus desavenencias con la mafia italiana, Montale vivía la vida sin creer en ella. Su existencia se manifestaba siempre en su lado oscuro, mostrando abiertamente no tener "apetito" alguno por vivir. Los amaneceres habían dejado de ser la ilusión de la belleza del mundo, puesto que, cuando éste abría los ojos, la realidad recobraba todos sus derechos, y, entonces, empezaba a percibirse el olor repugnante de lo cotidiano. El único medio que el héroe de Izzo encontrará para librarse de esa angustia, oliente mezcla de vida y muerte, será cocinar y disfrutar del sabor de los alimentos; deleitarse con suculentos platos 
condimentados con la originalidad de un gran chef o con el cariño casero; relajarse con una copa de vino al borde del mar; leer los poemas de Louis Brauquier (19001976); escuchar buena música ${ }^{3}$; comer con sus amigos; y, deleitarse con los besos y caricias de las mujeres que, con sus fragancias, perfumaban el alma de Marsella. Toda una serie de subterfugios con los que Montale conseguirá mitigar la desagradable fetidez que acosaba su existir.

\section{Lugares y rincones para sentarse a comer}

\subsection{La Guía Michelin y el "efecto Izzo"}

Hoy en día, en ciertos ámbitos literarios, se habla del "efecto Izzo", cuando se hace referencia a aquellas novelas, sobre todo policíacas, donde el autor aprovecha la trama del relato para añadir el nombre de algunos lugares reales. De este modo, la obra se convierte en una especie de guía turística con el atractivo aliciente de que el lector puede visitar aquellos sitios donde el protagonista come y bebe durante sus horas de relax y desconexión de la intriga (Roas, 2005: 55). Jean-Claude Izzo, en su trilogía, clasifica todos estos lugares siguiendo la regla de las tres B. (bars-bordelsboîtes de nuit), cuya norma responde a los establecimientos que suele frecuentar Fabio Montale (Izzo, 2006a: 224; Bertoncini, 2008: 50). En ellos, el protagonista comerá y beberá, respetando siempre la idiosincrasia del lugar, y disfrutando de la atmósfera que en ellos se genera.

Con todo, este método ya había sido utilizado por el escritor belga George Simenon (1903-1989) a través del personaje del comisario Jules Maigret. El protagonista de los polars de Simenon, pertenecía a la Brigade mobile de la police judiciaire de París, lo cual le permitía desplazarse por toda Francia y degustar, así, los diferentes platos de cada región. Se rumorea, además, que Simenon percibía un suplemento extra por parte de la Guía Michelin, si citaba uno u otro restaurante (Pino, 2009: 52). Con esta estrategia literario-comercial, los viajeros de la guía culinaria, podían comer y hospedarse, donde ya lo había hecho antes, en la ficción, el "raccommodeur des destinées" 4 . De igual modo, el novelista italiano Andrea Camilleri (1925-), seguirá la misma estela que Simenon, al crear al comisario Salvo Montalbano, quien, a lo largo de sus pesquisas, dará a conocer aquellas trattorias en las que podía comerse bien en Sicilia.

Izzo, frente a Simenon, quien llevará a Maigret por toda Francia, y al igual que Camilleri, se limitará a presentar lugares de su región, concretamente de su ciudad, lo que hará más auténtica su vinculación con las impresiones del lector-turista al reconocer los lugares frecuentados por Montale.

\footnotetext{
${ }^{3}$ Para el protagonista de Izzo, la música es un poderoso aliado para alejar ese olor a muerte que le persigue, siendo una clara muestra de ello el hecho de que, cada vez que entra en el Bar des Marấchers, Montale siente cómo el jazz ahuyenta esa hedionda pestilencia (Izzo, 1998: 25).

${ }^{4}$ Sobrenombre que se le daba al comisario Jules Maigret.
} 


\subsection{Un local de calor cosmopolita}

El Bar des Maraîchers, también conocido como el bar de Hassan, es el establecimiento más célebre de la trilogía de Jean-Claude Izzo. Este local se encuentra en lo alto de la estrecha rue Curiol, al final de la Canebière, justo a dos pasos de la plaza Jean-Jaurès. Se trata de un bar donde sus parroquianos confraternizan sin ninguna barrera de edad ni de sexo; sin tampoco importar el color de piel o el medio social al que pertenecen. En su ambiente, se siente la intensa presencia del cosmopolitismo marsellés, el cual se explica por los continuos brotes migratorios que ha experimentado la ciudad portuaria. Dicho fenómeno será descrito por Yvan Gastaut (2003: 2) como un "va-et-vient" que se erigirá como espina dorsal en la construcción de la identidad marsellesa ${ }^{5}$. En el Bar des Maraîchers, además, no se percibe el rechazo a la diferencia racial, sino que la atmósfera que se crea es de sincera fraternidad. Con todo, al margen de lo que ocurriera en determinados recintos, la aceptación de la diferencia y el racismo serán dos eternas constantes en esta urbe francesa, dos polos opuestos que, sin embargo, serán claves para la conformación de su identidad. Es significativo el orgullo que Montale siente al encontrarse en el bar de Hassan, sentimiento que procede de la satisfacción del saberse marsellés, pues él también posee raíces en el extranjero - al igual que $\mathrm{Izzo}^{6}$ - y, por lo tanto, es parte constituyente de esa mezcolanza multicultural que define la identidad marsellesa:

Ici, dans ce bar, chacun savait bien pourquoi il était de Marseille et pas d'ailleurs, pourquoi il vivait à Marseille et pas ailleurs. L'amitié qui flottait là, dans les vapeurs d'anis, tenait dans un regard échangé. Celui de l'exil de nos pères. Et c'était rassurant. Nous n'avions rien à perdre, puisque nous avions déjà tout perdu (Izzo, 1998: 22).

Así pues, en el Bar des Maraîchers, se descubre la fraternidad del emigrante que reconoce en el rostro del prójimo el de un amigo, un pariente o el de alguien que dejó en su país de origen. En el seno del bar de Hassan, como ocurre en el restaurante de Félix - otro amigo de Montale-, la amistad adquiere un rango mayor que el de la propia familia, dado que los lazos que se crean llegan a sustituir los vínculos consanguíneos (Izzo, 2006a: 127). Al dar a conocer la existencia de estos lugares y las relaciones que en su interior se generan, Izzo añadía un valor más a la noción de cosmopolita. La diversidad, la diferencia y la multiculturalidad, no sólo conformarán la identidad de la ciudad portuaria, sino que, además, consolidarán, y exacerbarán, ese sentimiento de pertenencia a un mismo lugar y el hecho de formar parte de él. Una emoción que se manifestará incluso por encima de las distintas tendencias políticas que pudieran tenerse, siendo ejemplo de ello el bar Péano, donde se reunían los periodistas de Le Provençal, La Marseillaise, l'A.F.P. y los de la Libération,

${ }^{5}$ Jean-Claude Izzo apuntará que Marsella, en realidad, pertenece a aquellas personas que han llegado a ella en busca de una vida mejor, siendo el exilio su elemento común: "Marseille appartient à l'exil. Son avenir appartient à ceux qui arrivent" (Izzo, 2006b: 394-396).

${ }^{6}$ Montale las tendrá en Italia; mientras que Izzo, también en España. 
sin que ello produjera conflicto alguno (Izzo, 2006a: 57), pues su única preocupación era el bien común de la ciudad.

\subsection{Otros recovecos para un bien manger}

Todos aquellos lugares de los que Jean-Claude Izzo habla tienen su propia idiosincrasia. Algunos bares o restaurantes son visitados por Montale, otros, por el contrario, sólo los cita en sus soliloquios de policía. Tras cada página de su trilogía, Izzo nos regala una nueva dirección de un bistrot, de un restaurant, de viñedos, nos ofrece descripciones precisas de bares, terrazas e incluso de rebordes de balcones donde es posible descansar bajo la fragancia de la menta y la albahaca (Vuillermet, 2005: 275). De este modo, si se desea degustar un buen plato de cocina marsellesa, se irá a L'Épuisette, en el pequeño puerto del Vallon des Auffes, sobre todo para comer la típica bouillabaisse (Izzo, 2006a: 294); aunque, si se prefiere algo más informal, podrá visitarse L'Oursin, cerca del Vieux-Port, uno de los rincones ideales para probar todo tipo de marisco: ostras, erizos de mar, almejas, vieiras, mejillones, etc. (Izzo, 2006b: 526). Lo cual nos demuestra que, una vez más, el mar es un excelente anfitrión cuando se trata de saborear la esencia de la cité phocéenne ${ }^{7}$.

Existen, no obstante, otros recovecos donde también es posible disfrutar de ese particular sabor salado que tienen algunos de los platos de susodicha ciudad. Uno de estos sitios es La Samaritaine, donde puede tomarse cualquier especialidad marsellesa, mientras se ve desfilar a la gente por la calle (Izzo, 1998: 231). Marse1la, además, también es una ville épicée, donde se encuentran todo tipo de especias, provenientes de tierras lejanas, igual que el cosmopolitismo que la caracteriza, haciendo de ésta una ciudad compleja, insondable e imposible de delimitar con un solo sabor. Montale, sabedor de este fascinante fenómeno, pasará siempre con el coche cerca del mercado de Longue-des-Capucins, para poder percibir el aroma del coriandro, del comino, del curry mezclado con menta... de toda una amalgama de esencias que lo llevarán hasta Oriente ${ }^{8}$ (Izzo, 2006a: 124). Ese será su particular viaje más allá de su hogar, porque Montale se verá anclado a las calles de Marsella, incapaz de abandonarla y eternamente preso de su exotismo:

Je n'avais aucun lendemain quand l'aube, comme à cet instant, se levait. Je n'avais jamais pris la mer sur un cargo. Je n'étais jamais parti à l'autre bout du monde. J'étais resté ici, à Marseille. Fidèle à un passé qui n'existait plus. À mes parents. À mes amis disparus. Et chaque nouvelle mort d'un proche ajoutait du plomb à mes semelles, et dans ma tête. Prisonnier de cette ville (Izzo, 1998: 77).

${ }^{7}$ Sobrenombre con el que se conoce Marsella, pues ésta fue fundada por marineros focenses hacia el 600 a.C.

${ }^{8}$ Montale describe Marsella como la puerta de Oriente, de la aventura y del sueño (Izzo, 2006a: 244-245). 
Marsella también se saborea de noche. Izzo nos habla de varios restaurantes donde puede comerse a altas horas de la madrugada, siendo uno de ellos Chez Mario, el cual se halla en la plaza Thiars. En este local, Montale cena con MarieLou, una joven prostituta antillana parecida a Diana Ross (Izzo, 2006a: 120). Pocas horas antes, la pareja se había encontrado en el O'Stop, otro restaurante nocturno ubicado en la plaza de l'Opéra, donde melómanos y prostitutas alternaban amigablemente (Izzo, 2006a: 115). Este recinto, nada tiene que ver con el pub que Izzo describe en Solea, cuyo nombre no menciona, pero sí resalta la nociva atmósfera que allí se respiraba. En el seno de este establecimiento, policías y delincuentes se mezclaban de tal forma que difícilmente podía distinguirse quien estaba de un lado u otro de la ley (Izzo, 1998: 137). Con todo, este lugar era ideal para cerrar negocios, aunque el escritor marsellés no especifica la naturaleza de éstos.

\section{Una filosofía para vencer a la muerte}

\subsection{Para sentirse vivo hace falta comer}

Fabio Montale hace suya esta divisa, para, así, anular toda parcela sombría que envuelve su existencia, la cual se había hecho más oscura desde la muerte de sus amigos de adolescencia, Ugo y Manu. Esta necesidad existencial por la comida y la buena cocina, Montale la manifestará del siguiente modo: “J'ai besoin d'ingurgiter des aliments, légumes, viandes, poissons, desserts ou friandises. De me laisser envahir par leurs saveurs. Je n'avais rien trouvé de mieux pour réfuter la mort. M'en préserver. La bonne cuisine et les bons vins. Comme un art de survivre" (Izzo, 2006b: 421; citado en Dhoukar, 2006: 36 y Vuillermet, 2005: 281). En cierto modo, este apego que revela el autor, es una forma de demostrar su amor por la vida.

Cocinar supone para Montale un estado de auténtica felicidad, sobre todo cuando esta actividad la realiza en compañía de sus amistades. Un momento para compartir, pero también de desconexión de la realidad, ya que cocinar requiere un determinado grado de concentración. Una vez lista la comida, los amigos se sientan a la mesa para degustarla, mientras recuerdan antiguas vivencias en común. Empero, a medida que la trilogía de Izzo avanza, Montale va perdiendo todos los referentes de ese pasado, hasta que, ya en Solea, sólo le quedará Didier Perez para poder evocar dichos recuerdos: "l'amitié, c'était cela, cette somme de souvenirs communs que l'on peut mettre sur la table en accompagnement d'un loup grillé au fenouil. Seul le 'Tu te souviens' permet de confier sa vie la plus intime, ces contrées de soi où règne le plus souvent la confusion" (Izzo, 1998: 167). En el polar de Izzo, existe, por lo tanto, un fuerte vínculo entre la comida y la amistad, dado que el placer que genera el disfrutar de un buen plato se intensifica cuando la complicidad de los comensales es sincera y está cargada de cariño.

Para Fabio Montale, desde siempre, comer bien había sido fundamental. Su recuerdo de infancia más desagradable fue cuando tenía nueve años, y, en una visita a Castel Giorgio, cerca de Salerno, se vio obligado a ingerir sólo pasta durante varias 
semanas (Izzo, 1998: 72). Desde aquella experiencia "traumática", nunca más volvió al país originario de su madre, además de no confiar en aquel que comiera cualquier cosa (Izoo, 2006b: 429). El ritual que llevan a cabo sus compañeros de policía, Pérol y Cerutti, al tomarse unas cervezas con unos sándwiches de tomate, anchoas y atún, éste, lo consideraba como una aberración (Izzo, 2006a: 187) —nada que ver con los sándwiches que Maigret se hacía con mimo, mejorándolos incluso al añadir dos lonchas de pan para que cupieran más ingredientes (Pino, 2009: 51). Montale evitará adquirir esa costumbre de comer "cualquier cosa", ya que consideraba que el verdadero sentido de cocinar era el desconectar de la realidad. Por eso, tomarse su tiempo para preparar un buen plato, pensando únicamente en los condimentos y en las medidas justas que tendría que aplicar para su buena elaboración, resultaba ser tan imprescindible como el hecho de saborear un guiso en su punto. Además, con ese tipo de "productos" de consumo rápido, no sólo se ingería la comida en sí, sino también los problemas de nuestra cotidianidad, puesto que dicho ritual preparatorio servía para "digerir” todos los sinsabores que nos envuelven.

\subsection{Una madre improvisada para un buen plato casero}

Jean-Claude Izzo no quiso privar a su protagonista de esa agradable sensación de volver a casa y poder comer un buen guiso. La madre de Montale hacía años que falleció, pero había una entrañable vecina a la que conocía desde su infancia, Honorine, quien le mantendrá la cena caliente y velará por su bienestar, pues lo consideraba como su propio hijo. Un amor que era recíproco, ya que Fabio la veía como "la mère des mères" (Izzo, 1998: 35). Izzo regalará a su personaje otro de los placeres del bien manger, aquel que sólo ofrece la acogedora atmósfera del hogar. Andrea Camilleri procederá del mismo modo con Salvo Montalbano, al crear a la Signora Angelina, la cual se encargará del cuidado de la casa del comisario, preparándole, también, algunas recetas caseras para que pudiera comer bien al regresar por la noche (Pino, 2009: 54-56). Angelina y Honorine, cubrirán esa parcela que a Montale y Montalbano les faltaba al no tener familia, aquella donde el calor del hogar dará un sabor especial a esos guisos dejados tarde sobre la encimera.

Entre los platos que cocinaba Honorine para Montale, encontramos las poutargues, una especialidad de Martigues, muy parecida al caviar (Izzo, 2006b: 371); espaguetis al pistou rellenos de legumbres de Hungría (Izzo, 2006b: 371; Vuillermet, 2005: 276); algunos deliciosos panisses (Izzo, 2006b: 344); su célebre foccacha, preparada con una base de pizza, sobre la que podían echarse los ingredientes que se deseara (Izzo, 2006a: 84-85); además de encargarse también del postre, al dejarle, de vez en cuando, un trozo de queso prolone (Izzo, 1998: 197); entre otros con el distintivo sello de un sincero amor de madre. 


\subsection{Las recetas de Jean-Claude Izzo}

Montale amaba cocinar, sobre todo cuando esta actividad se acompañaba de una buena pieza de jazz o blues ${ }^{9}$, cuidando todos los detalles de ese proceso, como si de un ritual se tratase, necesario, a su vez, para olvidar esa "saloperie du monde"10 en la que se veía envuelto. Izzo nos obsequia con algunas recetas que sigue su protagonista, al mismo tiempo que recoge las de otros personajes de la Trilogía - especialmente de Honorine-, ofreciéndonos, así, la posibilidad de compartir los sabores que en su obra describe. Todas ellas, son de platos tradicionales de Marsella, por lo que el modo de prepararlos no sólo depende de la maestría adquirida con la experiencia, sino que, además, conlleva cierta complicidad con esa mixtura de luz y mar que caracteriza a la cité phocéenne. Algunas de estas recetas son las siguientes:

\section{- La soupe au pistou:}

La soupe au pistou, il y avait mille façons de la préparer, sans doute. À Marseille, tout le monde disait : "Ma mère la faisait comme ça ", et la cuisinât donc à sa manière. C'était chaque fois un goût différent. Selon les légumes qu'on y mettait. Selon, surtout, comment on avait su doser l'ail et le basilic, puis la pommade des deux avec la pulpe de petites ébouillantées dans l'eau de cuisson des légumes. Honorine réussissait la meilleure de toutes les soupes au pistou. Haricots blancs, haricots rouges, haricots verts plats, quelques pommes de terre et des macaronis. Elle laissait cuire à feu doux tout le matin. Après, elle s'attaquait au pistou. À piler dans un vieux mortier en bois, l'ail et les feuilles de basilic (Izzo, 1998: 75-76; citado en Rosembert, 2007: 118-119 y Vuillermet, 2005: 277).

\section{- La poutargue:}

Il fallait en effet extraire les deux grappes d'œuf, sans déchirer la membrane qui les protège, les saler, les écraser, puis les faire sécher. Cela prenait bien une semaine, la préparation (Izzo, 2006b: 371).

\section{- Des poivrons farcis:}

Honorine avait une manière incomparable de faire des poivrons farcis. À la roumaine, disait-elle. Elle remplissait les poivrons d'une farce de riz, de chair à saucisse et d'un peu de viande de bœuf, bien salée et poivrée, puis elle recouvrait d'eau. Elle rajoutait coulis de tomate, thym, laurier et sarriette. Le goût était merveilleux, surtout si, au dernier moment, on versait dessus une cuillère de crème fraîche (Izzo, 2006a: 211).

\footnotetext{
${ }^{9}$ Así, en Total Khéops, vemos cómo Montale pasa toda la mañana cocinando una lubina al hinojo, escuchando viejas piezas de blues de Lightnin’ Hopkins (Izzo, 2006a: 147).

${ }^{10}$ Esa misma "saloperie du monde" que Montale consideraba que corría más rápido que nadie, porque, aunque pudiéramos olvidarla por un instante, terminaba siempre por atraparnos: "on pouvait l'oublier, la nier, elle nous rattrapait toujours au coin d'une rue"' (Izzo, 2006b: 405).
} 


\section{- Le loup grillé au fenouil:}

Après avoir nettoyé le loup, je l'avais rempli de fenouil, puis l'avais arrosé d'huile d'olive. Je préparai ensuite la sauce des lasagnes. Le reste du fenouil avait cuit à feu doux dans de l'eau salée, avec une pointe de beurre. Dans une poêle bien huilée, j'avais fait revenir de l'oignon émincé de l'ail et du piment finement haché. Une cuillerée à soupe de vinaigre, puis j'avais ajouté des tomates que j'avais plongées dans l'eau bouillante et coupées en petits cubes. Lorsque l'eau s'était évaporée, j'avais ajouté le fenouil (Izzo, 2006a: 147-148; citado en Rosembert, 2007: 119-120).

Siguiendo todos los pasos que el autor nos aconseja, no sólo se pueden degustar los platos regionales marselleses, sino también esa parcela de paz, amistad y relax que Montale vive junto a los suyos.

\section{El acompañamiento del alcohol}

\subsection{El vino, la exquisitez en el paladar}

Si para Fabio Montale el bien manger era lo más parecido a la felicidad, el alcohol, por el contrario, se manifestaba con una doble funcionalidad. Por un lado, servía para acompañar aquellos platos que tomaba en los bares, restaurantes o en casa de Honorine; mientras que, por el otro, le ayudaba a digerir la cruda realidad a la que se enfrentaba todos los días.

Para el protagonista del polar de Izzo, las bebidas alcohólicas eran excelentes complementos para alcanzar la senda que hacia ese estado de bienestar absoluto conducía la buena cocina. El sabor de la comida cobraba distintos matices, cuando, con ella, se ingería un vaso de alcohol determinado. Además, existía todo un conocimiento versado en saber cuándo, y en qué medida, había que acompañar una comida con uno u otro tipo de alcohol. Montale será un experto en esta faceta, sobre todo cuando se trataba de vino: la foccacha de Honorine la acompañará con una buena botella de Cassis Blanco (Izzo, 2006a: 85); la anchoada de Fonfon con una de rosado de Saint-Cannat (Izzo, 2006b: 323); los boquerones a la parrilla, con algo de vino de Bohemia (Izzo, 1998: 91); para la cocina griega, Montale elegirá un retsina blanco (Izzo, 2006a: 100); y, así, sucesivamente, demostrando su sensibilidad y respeto hacia el arte culinario. En ocasiones, éste comprará un par de botellas de vino tinto de Bandol, del tipo de Cagueloup, para luego meditar con qué comida podría beberlas (Izzo, 1998: 240). Con esta última experiencia, el héroe marsellés desafiaba su agudeza gustativa al invertir los elementos de la combinación para dar con la fórmula exacta. En cualquier caso, lo que no podía discutirse era que, para Fabio Montale, el comer y el beber eran dos actividades indisociables.

El vino, además, adquiría un sabor especial cuando se saboreaba en una de las terrazas portuarias de Marsella. Así, Montale disfrutaba de sus entrevistas con la comisario Hélène Pessayre con una botella de Trempier Blanc en el Vieux-Port (Izzo, 1998: 86 y 200), haciendo una pausa, cuando se terciaba, para tomar una copa de closs-cassivet, un delicioso blanco con efluvios de vainilla (Izzo, 2006b: 
362). En esta ocasión, el alcohol se encontraba huérfano de comida, aunque no dejaba de traer consigo el placer al paladar, pues el olor a mar era el que hacía precisamente más intenso el sabor del vino.

\subsection{El sortilegio del Lagavulin}

Otras bebidas, son, para Montale, un carburante para existir. Un trago amargo que lo animará a continuar en la cruel senda de crímenes, violaciones, asesinatos y otras atrocidades a las que tenía que hacer frente a diario. Entre todas ellas, es el Lagavulin, ese whisky escocés de ligero sabor a turba, la mejor ayuda para afrontar esa fría realidad (Izzo, 1998: 122; citado en Pino, 2009: 53). Su tan característico sabor instigará a Montale a reaccionar con acierto ante cualquier situación difícil, como aquella en la que halla a Cûc desnuda dispuesta a hacerle el amor (Izzo, 2006b: 492); o, cuando comprende que le quedan pocos minutos de vida tras recibir un tiro en la espalda, siendo consciente, entonces, que el olor a muerte había terminado por alcanzarlo: "Maintenant, la mort, c'est moi" (Izzo, 1998: 251). En un desesperado intento por aferrarse a la vida, el sabor del Lagavulin será el último que sentirá Montale en su paladar, presentándose, éste, como la más cruda metáfora de la vida misma.

Curiosamente, el protagonista del polar de Izzo sólo sentirá placer en esta bebida cuando escuche la música que posee el sabor amargo de la realidad, según éste, la de Gianmaria Testa o la del bandoneón de Astor Piazzola ${ }^{11}$ acompañando a Jerry Mulligan (Izzo, 1998: 216; Izzo, 2006a: 200). Una singular correspondencia que no se repetirá con otras músicas, ni tampoco con otras bebidas.

Dada su naturaleza sibarita, Fabio Montale nunca beberá whisky de mala cali$\mathrm{dad}^{12}$, sino que buscará degustar otras variedades de este licor, en función de las circunstancias en las que se encuentre. Así, veremos cómo, en casa de Fonfon y Honorine, tomará una botella de Bunan para jugar al rami ${ }^{13}$ (Izzo, 1998: 122); se servirá un vaso de Oban para brindar con Sébastien y Hassan tras haber recibido los cinco disquetes que Babette le había mandado sobre los negocios sucios de la Maffia (Izzo, 1998: 127; Pino, 2009: 53); u, optará por un Glenmorangie para disfrutar mejor de la cena con Marie-Lou en Chez Mario (Izzo, 2006: 121). Esto nos lleva a corroborar que el Lagavulin es el único brebaje que tendrá ese mismo sabor desagradable que posee la vida que lleva Montale.

\footnotetext{
${ }^{11}$ Montale opina que el tango sirve para hundirse en la amargura de la nostalgia (Ibid.: 562, 564).

${ }^{12}$ Esta reticencia a beber cualquier tipo de whisky la constatamos en Chourmo, cuando Saadna ofrece a Montale un vaso de whisky, que desprendía un olor nauseabundo, además de tener cierta textura de caldo infecto (Ibid.: 381 ).

${ }^{13}$ Juego que se practica con 52 cartas más un joker entre dos, tres, cuatro o cinco jugadores.
} 


\subsection{El pastis, el arte de vivir marsellés}

Con una mezcla de anís y regaliz, el pastis de Marsella, dotado de una graduación de $45 \%$, es la bebida regional que Montale más exalta dentro de su particular ruta gastronómica. El pastis, al igual que ocurría con el Lagavulin, desempeñará ese doble rol de deleite y apoyo para afrontar la dura realidad cotidiana. Así, por ejemplo, el ex policía beberá un vaso de pastis para relajarse en la cita que tiene con Hélène Pessayre en la terraza de Chez Ange (Izzo, 1998: 91), pero también se hará con una botella de pastis para ahuyentar los problemas, mientras se prepara unas doradas a la plancha (Izzo, 2006b: 344). En esos momentos en los que el pastis se bebe para acompasar el ritmo de las sensaciones que inundan el paladar, la música desempeñará también un papel importante. Sin embargo, a diferencia de lo que ocurría con el Lagavulin donde el tango se imponía, la música ideal para el pastis será el jazz, y, en especial, el de Nat King Cole (Izzo, 1998: 186). Para Fabio Montale, además, el pastis, junto a la kémia ${ }^{14}$, constituyen el "art de vivre marseillais" (Izzo, 2006b: 389). Izzo concede un doble valor a todo aquel elemento oriundo de Marsella, dotándolo de un matiz positivo que lo transforma en algo que le es propio.

\section{Del sabor y perfume de la mujer marsellesa}

\subsection{Aquello que Montale busca en las mujeres}

El héroe de la trilogía de Jean-Claude Izzo no consigue averiguar qué es lo que busca en las mujeres. Lo malo es que mientras que no logre saberlo, no dejará de herirlas. Esta condena de ser incapaz de hacer felices a las mujeres, no obstante, la asumirá como algo innato en su propia persona (Izzo, 2006b: 529). Todas sus relaciones serán conflictivas, sin que llegue a aprender nunca cómo conservar a una mujer a su lado. Muriel, Carmen o Alice, no importaba quien fuera, la misma historia se repetía una y otra vez (Izzo, 2006a: 86). Según Rosa, la mujer que más tiempo estuvo con él, antes de irse, había dicho a Montale que todo esto le ocurría porque éste tenía una visión limitada del mundo.

Sin embargo, el protagonista de Izzo había amado a todas las mujeres que pasaron por su vida. Todas ellas le habían dado su tiempo, y eso era ya mucho, porque, según éste, "le temps est une chose essentielle dans la vie d'une femme" (Izzo, 2006a: 123). Montale confesaba haber disfrutado profundamente de las mujeres, en tanto que concebía que el placer que pudiera sentirse con ellas, pasaba por tratarlas con deferencia y consideración (Izzo, 2006a: 209-210). Empero, Izzo no se desvinculaba del discurso patriarcal, pues, para éste, la mujer ideal era una mezcla de madre, hermana y prostituta: Honorine, Babette y Marie-Lou (Izzo, 2006a: 209-

\footnotetext{
${ }^{14}$ Bebida que se sirve en los aperitivos y que tiene también gusto de anís.
} 
210). Esto nos demuestra que el escritor marsellés no intentaba crear un héroe feminista, sino continuar con el estereotipo masculino del polar clásico.

Marina Pino (2009: 57) cree que la mala suerte que, en materia de mujeres, persigue a Montale, es necesaria para que éste pueda cumplir con el cometido que Izzo le otorga, no siendo otro que el de saborear los placeres que le ofrece Marsella. Si su protagonista hubiera estado casado y fuera padre de familia, tendría que estar siempre en el hogar a la hora de comer y cenar, privándose, y al público lector con él, de la posibilidad de degustar distintos platos en otros lugares; de sentir las diferentes gamas de música con las que ambientar una buena comida o relajarse con una copa de whisky en un bar nocturno; o, de dejar que el olor de la piel de otras mujeres penetrara hasta lo más profundo de su ser. En este último caso, Alexandra Schwartzbrod (1998) añadirá que Izzo, al igual que Montale, era un auténtico "bouffeur de femmes", aunque en el sentido de devorar el aroma que éstas desprendían.

\subsection{La atracción de la exótica diversidad femenina}

Jean-Claude Izzo, al igual que Fabio Montale, creía en la libertad de las mujeres y en la confianza mutua de la pareja, pero el miedo ${ }^{15}$ y la muerte, con su fétido olor, transformarán su poesía sensitiva. Los aromáticos versos de su prosa ensalzan, en todo momento, la identidad femenina marsellesa, describiendo con delicadeza, y sensibilidad, los olores que emanan de las mujeres que conoce el héroe de la Trilogía. Sin embargo, la dura realidad de Marsella, cruelmente delineada por un panorama de prostitución, crimen y violencia, afectará al autor de tal manera que imprimirá esa esencia urbana sobre el aroma-base de dichas mujeres. En este sentido, el escritor marsellés restará gran parte de esa inicial carga poética a los personajes femeninos con los que intime el protagonista de su polar, aunque sin quitarles atractivo alguno. Nadia Dhoukar (2006: 19) corrobora esta hipótesis al señalar que el autor marsellés escribe sobre la sensualidad, sobre un erotismo que se mezcla con la identidad de la ciudad portuaria y sus mujeres. Así, Montale mostrará una actitud receptiva para disfrutar de todas aquellas sensaciones que le brinde la vida, no sólo con la comida, la bebida o la música, sino también con las mujeres que ame.

A lo largo de la trilogía de Izzo, los olores que exhalarán las amantes del héroe marcarán los recuerdos que de ellas éste tenga, quien, además, encontrará, en la piel de todas ellas, los condimentos, especias y aromas, que también apreciará en las comidas:

- Lole, menta y albahaca:

Lole es el noir désir de los tres amigos: Manu, Ugo y Fabio. Es el más grande amor de Montale. Su cuerpo es dulce y, desprende un aroma de menta y albaha-

\footnotetext{
${ }^{15}$ Para Fabio Montale, el miedo de los habitantes de Marsella al extranjero, no sólo les impide pensar, sino sobre todo repensarse a sí mismos (Izzo, 2006a: 128).
} 
ca (Izzo, 1998: 153; 2006a: 68). Tras la marcha de Lole a Sevilla, de donde es originaria, Fabio impregna su apartamento de menta y albahaca con el objeto de preservar el aroma que generaba la piel de la española (Izzo, 2006a: 130 y, 302).

- Marie-Lou, un cuerpo sazonado:

Marie-Lou es una joven prostituta antillana que trabaja en el $O$ 'Stop, un restaurante nocturno situado en la plaza de l'Opéra. Sus rasgos físicos son sumamente hermosos, evidencia de la que ella misma es consciente, pues confiesa a Montale que era demasiado bonita como para ser una mujer honesta (Izzo, 2006a: 220). Puede que por esa razón, en su cuerpo, se distinguieran tanta variedad de especias: almizcle, canela, pimienta y albahaca (Izzo, 2006a: 122).

- Cûc, olores jamás conocidos:

Antes de enfermar de cáncer de pulmón, Jean-Claude Izzo había proyectado viajar a Vietnam, país que siempre despertó su atención. En Chourmo, Izzo halla el modo de exteriorizar esa fascinación encarnándola en Cûc, la mujer vietnamita de Adrien Fabre, el asesino de la segunda parte de su trilogía. Cûc evocará al policía ya retirado toda clase de aromas y perfumes, que, sin embargo, éste será incapaz de reconocer: "Sa tête se posa sur mon épaule. Je ne connaissais pas le Vietnam, mais toutes ses odeurs vinrent à ma rencontre. Dès qu'il y a du désir quelque part, pensai-je, il y a des odeurs différentes" (Izzo, 2006b: 492). Todos esos olores serán imaginarios para Izzo, pero su deseo por conocerlos quedará siempre latente en su alma de escritor.

\section{- Sonia, sabor salado de mar}

Sonia provenía de la región italiana de Abruzzo, la cual se encuentra bañada por el mar Adriático. Montale siente ese sabor salado de mar sobre Sonia cada vez que acerca sus labios a su espalda (Izzo, 1998: 71).

\section{- Leila, un fuerte olor a resina}

Leila nunca llegará a mantener relaciones sexuales con Montale, aunque la joven universitaria argelina lo deseaba. El todavía policía no se atreverá ni siquiera a insinuársele, sobre todo debido a la diferencia de edad que existía entre ambos, pero no podrá evitar imaginar un fuerte olor de resina de pinos sobre su piel, un olor que le envolverá en la más pura sensualidad: "Le désir me gagnait. Il était tôt, mais la chaleur libérait déjà les fortes odeurs de résine des pins. J'imaginai cette odeur de résine entre les cuisses de Leila. Le goût que cela pouvait avoir sur ma langue" (Izzo, 2006a: 272). Desafortunadamente, éste nunca podrá descubrir si Leila olía de este modo, ya que la estudiante será violada y asesinada por un grupo de fanáticos racistas.

Valiéndose de Fabio Montale, Izzo hace hablar a Marsella a través de los perfumes naturales y de la aromática sensualidad que desprenden los cuerpos de todas estas mujeres, fruto, sin duda, de la realidad multicultural de la cité phocéenne. 


\section{Conclusión}

Fabio Montale apunta que la verdadera vida es aquella en la que la felicidad se construye a partir de petits riens insignifiants. En ocasiones, está puede convertirse en un caos inmenso, un auténtico Total Khéops, como apuntan los raperos de IAM, pero sin que por ello deje de ser hermosa. Sólo basta con aprender a saborearla y a conocer aquellos olores que la envuelven, aunque algunos puedan ser desagradables.

Izzo crea un personaje con el don de saber apreciar esos petits riens, pero también con la capacidad de percibir el mal olor que cubre su propia existencia y la sociedad marsellesa en general. Esta ciudad portuaria es un gran laboratorio en el que pueden distinguirse diversas formas de sociabilidad, pero también una atractiva multiculturalidad que se percibe a través de la seducción de sus olores. El escritor marsellés nos hablará de la sensualidad de las vidas sin esperanza, como la de aquellas mujeres a las que amará y cuyos olores quedarán impresos en su memoria. Son éstos aromas de amor y también de una identidad nacional a partir de la cual se ha construido Francia. Izzo no quiso que su protagonista tuviera una relación con una mujer blanca y burguesa, sino que sus amantes fueran oriundas de otros lugares, pero sin dejar de ser integrantes de la ciudad. Por ello, el escritor francés, en Chourmo, señalará que Marsella pertenece al exilio, a todas aquellas personas que llegan a ella desde lejos. La trilogía de Izzo, en cierto modo, puede concebirse como otro manual de supervivencia de esa particular cultura mediterránea que posee el arte de mezclar el carácter abierto de sus gentes con el multicultural dinamismo del presente. Ese olor a muerte que percibe Fabio Montale no es más que el que se desprende del miedo, y el odio, a esa mezcolanza de identidades que, en realidad, son una sola. Izzo confesará este hecho en Total Khéops, recalcando, además, que esa nociva sensación impide a los habitantes de la ciudad portuaria adaptarse a esa continua situación de cambio, incapacitándolos, a su vez, para resignificarse a sí mismos.

Todo este trayecto itinerante que sigue Montale a lo largo de sus aventuras, llevándolo a bares y a restaurantes, donde conocerá deliciosos platos de comida, bebidas regionales, músicas variadas y/o personas de todo tipo, será la prueba fehaciente de la multiculturalidad propia de muchas ciudades mediterráneas. La Maffia simboliza el rechazo de ésta, puesto que los crímenes que se cometen en las tres novelas son causa del racismo y del oscuro deseo de preservación de un sistema que no acepta al extranjero. Es cierto que este fenómeno genera miseria, patente en los barrios del norte de Marsella, pero también cubre de un fuerte atractivo a la luz y al mar que "sazonan" la ciudad. Del mismo modo, el exótico equipaje que los recién llegados traen consigo infunde toda una amalgama de sabores y olores, que, si bien no consigue solapar el mal olor, al menos, deja impreso en sus calles un leve aroma a esperanza. 


\section{REFERENCIAS BIBLIOGRÁFICAS}

Bertoncini, P., (2008) "Mise en scène de situations sociolinguistiques dans Mafio$s a$ " in Glottopol [En línea]. $\mathrm{N}^{\mathrm{o}} 12$, disponible en: http://www.univrouen.fr/dyalang/glottopol/numero_12.htm [Último acceso el 3 de enero de 2012].

Dhoukar, N., (2006) "Jean-Claude Izzo. Trajectoire d'un homme" in Izzo, J.-C., La trilogie Fabio Montale. Paris, Folio Policier, pp. 7-41.

Gastaut, Y., (2003) "Marseille cosmopolite après les décolonisations : un enjeu identitaire" in Cahiers de la Méditerranée [En línea]. $\mathrm{N}^{0}$ 67, disponible en: http://cdlm.revues.org/index134.html [Último acceso el 13 de mayo de 2012].

Gastaut, Y., (2002) "Le cosmopolitisme, un univers de situations" in Le cosmopolitisme [En línea]. $\mathrm{N}^{\mathrm{o}} 8$, disponible en: http://urmis.revues.org/index21.html [Último acceso el 1 marzo de 2012].

Izzo, J.-C., (2006a) Total Khéops in Izzo, J.-C., (2006c) La trilogie Fabio Montale. Paris, Folio Policier, pp. 46-304.

Izzo, J.-C., (2006b) Chourmo in Izzo, J.-C., (2006c) La trilogie Fabio Montale. Paris, Folio Policier, pp. 305-579.

Izzo, J.-C., (1998) Solea. Paris, Gallimard, coll. Série Noire.

Lassave, P., (1999) "La ville entre les lignes de la science et du roman" in Espaces et sociétés. $\mathrm{N}^{\circ}$ 94, pp. 11-29.

Perron, G., (2003) "Jean-Claude Izzo : entre la tragédie et la lumière" in Québec français [En línea]. $\mathrm{N}^{\mathrm{o}} 128$, disponible en: http://id.erudit.org/iderudit/55775ac [Último acceso el 4 de febrero de 2012].

Roas, D., (2005) “¿Por qué leemos (todavía) novelas policíacas?” in Quimera. № 259-260, julio-agosto, pp. 54-59.

Pino, M., (2009) "Tres comisarios se sientan a la mesa: Maigret, Montale y Montalbano" in Dossier ObT. Literaturas. No 5, pp. 46-58.

Puntí, J., (2009) "Olor de anís en Marsella" in El Periódico de Aragón [En línea]. Disponible en: http://www.elperiodicodearagon.com/noticias/escenarios/olor-aanis-en-marsella 518803.html [Último acceso el 2 de marzo de 2012].

Rosembert, R., (2007) Sabores que matan. Comidas y bebidas en el género negrocriminal. Buenos Aires, Paidós.

Schwartzbrod, A., (1998) "Jean-Claude Izzo, 52 ans, auteur de polars, vient d'achever une trilogie marseillaise sur fond de désespérance, de racisme et de violence" in Libération [En línea]. Disponible en: http://www.liberation.fr/portrait/0101245977-jean-claude-izzo-52-ans-auteur-depolars-vient-d-achever-une-trilogie-marseillaise-sur-fond-de-desesperance-deracisme-et-de-violence-le-marius-etait-en-noir [Último acceso el 13 de enero de 2012]

Vuillermet, M., (2005) "Boire et manger chez Jean-Claude Izzo ou la nourriture des justes" in Piarotas, M. \& Charreton, P., Le Populaire à Table. Le Boire et le Manger aux XIX $X^{e}$ et $X X^{e}$ siècles. Saint-Étienne, Publications de 1'Université de Saint-Étienne, pp. 275-283. 